Grance NBS

erence Publi-

ivuo opecia.

Publication

$480-31$

A IIIOJ 09137?

\title{
Transfer of \\ Monochrome \\ Video Information \\ from Magnetic \\ Tape to Motion \\ Picture Film \\ for Archival \\ Storage
}

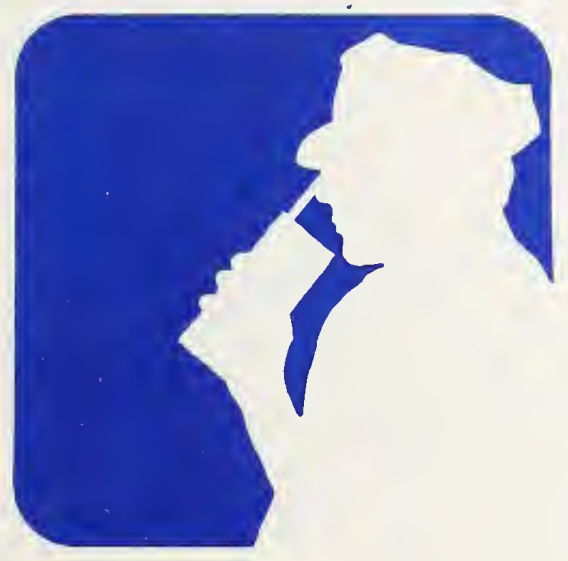

Law Enforcement

Equipment

Technology

\section{U.S. DEPARTMENT OF \\ COMMERCE}

National Bureau of

Standards

$480-31$

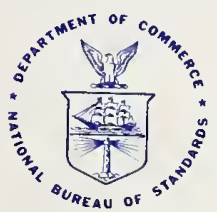




\section{ACKNOWLEDGMENTS}

This document was prepared by the Law Enforcement Standards Laboratory of the National Bureau of Standards under the direction of Lawrence K. Eliason, Manager of the LESL Security Systems Program, and Jacob J. Diamond, Chief of LESL. The research was sponsored by the National Institute of Law Enforcement and Criminal Justice, Lester D. Shubin, Program Manager for Standards. 
NBS Special

Publication 480-31

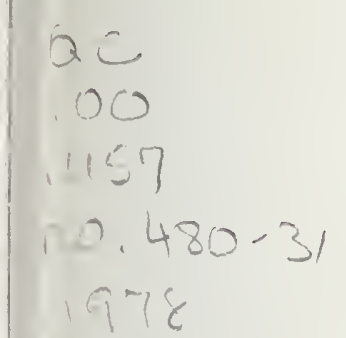

\section{Transfer of}

Monochrome

Video Information

from Magnetic

Tape to Motion

Picture Film

for Archival

Storage

Prepared by

Joseph C. Richmond

Center for Consumer Product Technology

National Bureau of Standards

and the

Law Enforcement Standards Laboratory

Center for Consumer Product Technology

National Bureau of Standards

Washington, D.C. 20234

prepared for

National Institute of Law Enforcement

and Criminal Justice

Law Enforcement Assistance Administration

U.S. Department of Justice

Washington, D.C. 20531

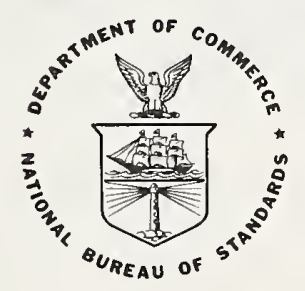

Issued May 1978
U.S. DEPARTMENT OF COMMERCE, Juanita M. Kreps, Secretary Dr. Sidney Harman, Under Secretary Jordan J. Baruch, Assistant Secretary for Science and Technology NATIONAL BUREAU OF STANDARDS, Ernest Ambler, Director 
Library of Congress Catalog Card Number: 78-600045

National Bureau of Standards

Special Publication 480-31

Nat. Bur. Stand. (U.S.), Spec. Publ. 480-31, 14 pages

CODEN: XNBSAV

U.S. GOVERNMENT PRINTING OFFICE

WASHINGTON: 1978

For sale by the Superintendent of Documents, .

U.S. Government Printing Office, Washington, D.C. 20402

Stock Number 003-003-01932-1 Price 90 cents

(Add 25 percent additional for other than U.S. mailing). 


\title{
FOREWORD
}

The Law Enforcement Standards Laboratory (LESL) of the National Bureau of Standards (NBS) furnishes technical support to the National Institute of Law Enforcement and Criminal Justice (NILECJ) program to strengthen law enforcement and criminal justice in the United States. LESL's function is to conduct research that will assist law enforcement and criminal justice agencies in the selection and procurement of quality equipment.

LESL is: (1) Subjecting existing equipment to laboratory testing and evaluation and (2) conducting research leading to the development of several series of documents, including national voluntary equipment standards, user guidelines, and technical reports.

This document is a law enforcement equipment report developed by LESL under the sponsorship of NILECJ. Additional reports as well as other documents are being issued under the LESL program in the areas of protective equipment, communications equipment, security systems, weapons, emergency equipment, investigative aids, vehicles and clothing.

Technical comments and suggestions concerning the subject matter of this report are invited from all interested parties. Comments may be addressed to the author or the Law Enforcement Standards Laboratory, National Bureau of Standards, Washington, D.C. 20234.

\author{
Jacob J. Diamond, Chief \\ Law Enforcement Standards \\ Laboratory
}




\section{CONTENTS}

Foreword

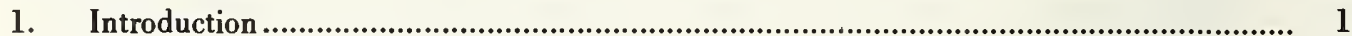

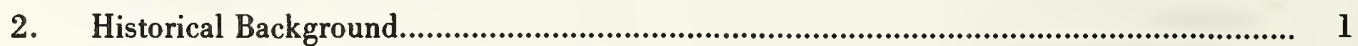

3. Storage and Use of Videotape ........................................................................... 2

4. Processing and Storage Conditions for Archival Motion Picture Film ............................ 2

5. Problems Involved in Photographing Video Images ..................................................... 2

6. Solutions to the Synchronization Problem ...................................................................... 3

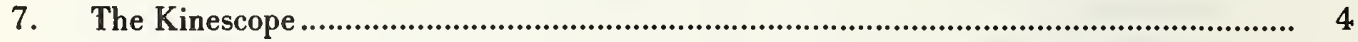

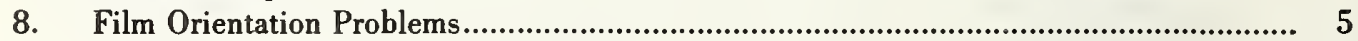

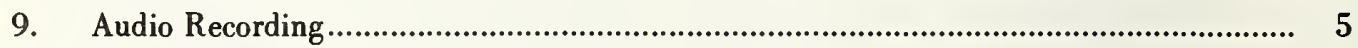

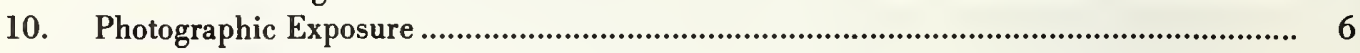

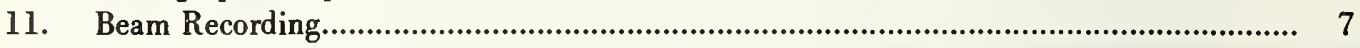

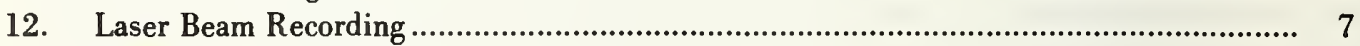

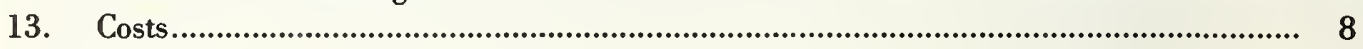

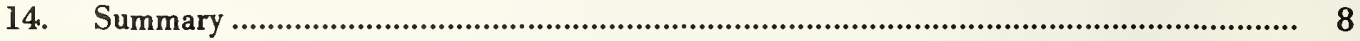

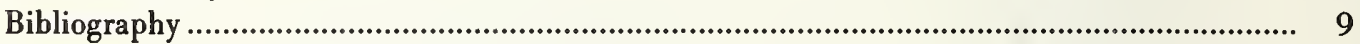




\title{
TRANSFER OF MONOCHROME VIDEO INFORMATION FROM MAGNETIC TAPE TO MOTION PICTURE FILM FOR ARCHIVAL STORAGE
}

\author{
Joseph C. Richmond \\ Center for Consumer Product Technology, National Bureau of Standards, Washington, D.C. 20234

\begin{abstract}
Magnetic tape, and particularly video magnetic tape, is not an archival material. Measurable deterioration occurs in a period of 5 years, and noticeable deterioration in 20 years. Motion picture film, on the other hand, is considered to be an archival material when properly processed, handled and stored. This report describes several methods used to transfer video information from magnetic tape to motion picture film. These include kinescope recording, using the midfield splice or rapid pulldown method of synchronizing frame rates, electron beam recording and laser scanner recording.
\end{abstract}

Key words: Archival storage; electron beam recording; kinescope recording; laser scanner recording; magnetic tape; midfield splice; motion picture film; rapid pulldown; video tape.

\section{INTRODUCTION}

The monochrome video tape recording of expert testimony, depositions, and even complete trials, is coming into increased use. The archival storage of such court records is thus of great interest to court administrators. However, magnetic tape, either audio or video, is not an archival material. The tape deteriorates with time and with use in two ways. First is physical deterioration of the tape itself, and particularly of the binder that provides the cohesion of the magnetic coating and the adhesion of the coating to the backing. There is also mechanical erosion of the magnetic coating during recording and playback, which may be accentuated by poor cohesion of the coating, or by the presence of dust or other contamination on the tape or heads. Second is loss of magnetism of the magnetic particles, which may be triggered by stray magnetic fields, temperature changes or mechanical shock. Print through is another manifestation of magnetic change, in which the signal from one layer of tape is partially transferred to adjacent layers, due to the magnetic field of the tape itself. Such print through may be enhanced by weak extraneous magnetic fields or other conditions that are not strong enough to demagnetize the tape by themselves.

Monochrome silver halide motion picture film, on the other hand, is approved as an archival material when properly processed and stored. This report outlines the procedures that are used to convert monochrome audio and video information from magnetic tape to motion picture film.

\section{HISTORICAL BACKGROUND}

Videotape recording was initially developed for broadcast use in 1956, with the introduction of the quadruplex system, initially priced in excess of $\$ 100,000$. This device came into rather widespread use in television broadcasting studios over the next 10 years, but the price remained so high that it was rarely used for any other purpose.

The development of helical-scan recorders occurred during the late 1960's, and by 1970 their quality had been improved and their cost reduced to a point where they found widespread use in closed-circuit television, surveillance, and general-use systems. The cost of complete recording systems of camera and recorder has already dropped to less than $\$ 1,500$, and may well decrease further.

Because of the fairly recent development of videotape recording systems, and particularly helical-scan recorders, there is no large body of experience on which to base estimates of the 
useful life of a videotape recording. However, experience with audio and computer magnetic tape may be pertinent, remembering that most computer data storage is in digital form, and can be fully recovered even though a reduction in pulse amplitude of 50 percent or more may have occurred. Such experience leads to the conclusion that for good tape, properly stored and rarely played, there will probably be no noticeable deterioration of image quality in 5 years, even though some deterioration may be detected instrumentally. After 20 years, it is expected that there will be some noticeable deterioration of image quality, but the tape should still be usable. For tapes not properly stored, or that have been played back repeatedly, deterioration will be more rapid.

The deterioration of video tape with time is considered by the National Archives to be sufficiently serious to warrant their routinely converting the national news programs of the major television networks from videotape to motion picture film for archival storage.

\section{STORAGE AND USE OF VIDEOTAPE}

The recommended conditions for the storage of videotape are: (1) each individual roll of tape should be spooled under a uniform tension of 40 to 60 grams force (gf), and enclosed in a dust-proof container; (2) the containers should be stored on edge on metal shelves; (3) the shelves should be in an enclosure, held under a slight positive atmospheric pressure of clean dust-free air at a temperature of $22 \pm 2{ }^{\circ} \mathrm{C}$ and relative humidity of $50 \pm 5$ percent; (4) the tapes should be rewound, or played, at least once a year, and again spooled under a uniform tension of 40 to 60 gf.

For use the tape should preferably be removed from its container in a clean, dust-free atmosphere and played on a playback machine with clean heads. The dust-free playback area should be completely enclosed. Only lint-free clothing should be worn, and smoking, eating and drinking should be prohibited in the playback or rewind area. Before being returned to storage the tape should be spooled under a constant tension of 40 to $60 \mathrm{gf}$.

\section{PROCESSING AND STORAGE CONDITIONS FOR ARCHIVAL MOTION PICTURE FILM}

Monochrome silver halide motion picture film, if properly processed and stored, has been found to be an archival material. Photographic negatives made over 100 years ago are still in excellent condition.

The principal precaution in processing film for archival storage is that the film be thoroughly washed as the last stage of processing, to remove the photographic fixer, sodium thiosulphate. The film should also be dried in a dust-free atmosphere. The conditions for the archival storage of motion picture film are similar to those for videotape, with one exception. The atmosphere should be completely free from any traces of sulfate or sulfite vapors or peroxide formers. This essentially means that the film should be stored in metal containers, in the absence of any paper or paper products. The presence of sulfite-process paper products, particularly in the presence of high humidity, can lead to very significant degradation of the film.

\section{PROBLEMS INVOLVED IN PHOTOGRAPHING VIDEO IMAGES}

The major problem in photographing video images with a motion picture camera is the difference in frame rates. The standard frame rate for motion picture film is 24 frames per second; that for television is 30. Each video frame consists of two fields, hence there are 60 video fields per second, or 2-1/2 fields per motion picture frame, or 4 motion picture frames per 5 video frames. As a further complication, the pull-down time of the normal motion picture camera, while the shutter is closed between exposures, is longer than the vertical blanking interval between video fields.

There are other problems. The picture tube of a video monitor is never completely dark or completely illuminated at any one time. The decay time of the phosphor in the picture tube is usually on the order of $1 / 3$ to $1 / 2$ the field time; hence a bright band, $1 / 3$ to $1 / 2$ the height of 
the picture tube, appears at the top of the tube and moves down the face of the tube, and a dark band, $1 / 2$ to $2 / 3$ the height of the tube follows each bright band. At any one instant of time there may be a single bright band on the tube, with dark bands above and below it, or a single dark band, with bright bands above and below it. In order to obtain uniform exposure of each frame of motion picture film, the camera shutter must be open for a time corresponding to an integral number of TV frame times. If the frame rates are not synchronized, and the time is longer than an integral number of frame times, part of the motion picture frame is overexposed; if the time is shorter, part is underexposed.

Other problems with trying to photograph the image displayed on a normal television receiver are focus and distortion. In order to keep the picture tube short, to reduce the size of the receiver, a wide-angle electron gun must be used; this introduces some geometric distortion into the video image. In addition, to keep the electron beam in better focus, it is necessary to curve the phosphor screen; hence most television receivers have convex phosphor screens. The luminance of the phosphor screen is low, and in order to get proper exposure, a fast lens of limited depth of field must be used, which throws some areas of the screen out of focus.

To solve the problems involved in photographing a video image, a special device called a kinescope has been developed. This is a special television monitor and is used with a motion picture camera that has its shutter synchronized to the frame rate of the video image.

\section{SOLUTIONS TO THE SYNCHRONIZATION PROBLEM}

The problem of synchronizing the action of the motion picture camera to that of the video monitor basically means that one out of every five video fields or frames must be blanked off, and each motion picture frame exposed to exactly two TV fields. This means that the 60 TV fields per second must be reduced to 48 fields, recorded on 24 motion picture frames. Two different types of equipment have been developed to accomplish this synchronization.

The first procedure is called the midfield splice (see fig. 1 and table 1). A camera frame rate of 24 frames per second is used. The period is thus $41.667 \mathrm{~ms}$, during which the shutter is open

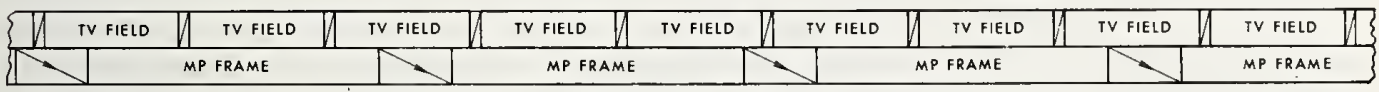

$$
\text { D vertical blanking interval }
$$

FIGURE 1. Timing relationships between field rate of video image and frame rate of midfield splice motion picture camera .

TABLE 1. Time periods for television scanning motion picture camera shutters

\begin{tabular}{lr}
\hline \multicolumn{1}{c}{ Television Scanning } & $\mathrm{ms}$ \\
Frame Time & 33.333 \\
Field Time & 16.667 \\
Vertical Blanking Time & 1.250 \\
Active Scan Time Per Field & 15.417 \\
$\quad$ & \\
$\quad$ MP-Midfield Splice & \\
Frame Time & 41.667 \\
Shutter Open Time & 33.333 \\
Shutter Closed Time & 8.333 \\
\multicolumn{1}{c}{ MP-Rapid Pulldown } & \\
Frame Time & 33.333 \\
Shutter Open Time & 132.082 \\
Shutter Closed Time & 34.583 \\
Pulldown Time & $<1.000$ \\
\hline
\end{tabular}




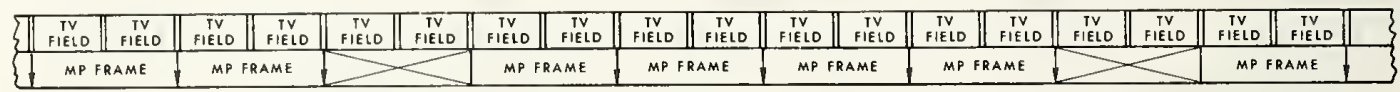

đVertical blanking interval

FIGURE 2. Timing relationships between field rate of video image and frame rate of rapid pulldown motion picture camera.

for $33.333 \mathrm{~ms}$, and closed for $8.333 \mathrm{~ms}$. The normal field rate of the video picture is 60 fields per second, or $16.667 \mathrm{~ms}$, of which about $1.250 \mathrm{~ms}$ is flyback time during which there is no scanning. If these time relationships are maintained, each motion picture (MP) frame will be exposed to exactly two video fields, with half a video field period blocked by the shutter after each frame is exposed. Normally, these two video fields will comprise portions of three fields; first the frame will be exposed to part of one field, then a complete field, then part of the next field, but the total exposure will be exactly equal to two complete fields. If the ratio of the two frame rates is not held to $5 \mathrm{TV}$ frames to $4 \mathrm{MP}$ frames, a portion of the film will be improperly exposed. If the TV ratio is greater than 5 to 4 , the MP frames will be overexposed where the portions of the first and third fields overlap. If the ratio is less than 5 to 4 , the frames will be underexposed in the gap between the portions of the two fields. The defect due to under or overexposure of alternate frames is called shutter bar or banding. It is not easy to keep the ratio of the two speeds exactly at 5 to 4 ; hence this defect is common in films produced by this procedure. For this reason the midfield splice is not used much where the highest quality in the motion picture image is desired.

The second process will be called the rapid-pulldown method (see fig. 2 and table 1). In effect, the vertical blanking interval acts as the shutter for the film pulldown, which is accomplished in less than $1 \mathrm{~ms}$ by carefully timed bursts of compressed air. There are no mechanical cams or claws for film pulldown. The shutter blanks off each 5th TV frame, and has a period of $166.667 \mathrm{~ms}$, being open for $133.333 \mathrm{~ms}$ and closed for $33.333 \mathrm{~ms}$. The exposure time for each MP frame is about $32.3 \mathrm{~ms}$. The bursts of compressed air are accurately synchronized with the vertical blanking intervals of alternate TV fields through a camera drive inverter. Film pulldown occurs at every second vertical blanking interval for four frames. At the end of the fourth frame the shutter closes and blanks out the fifth TV frame. The shutter then opens, and a new cycle of four frames starts. One out of every five TV frames is not photographed, to maintain the proper synchronization between the two frame frequencies. This is the preferred method of converting videotape signals to motion picture film.

\section{THE KINESCOPE}

The kinescope is a video monitor that varies in several respects from a normal TV monitor or receiver. The picture tube has an optically flat face, and its length is considerably greater than that of a normal picture tube. The greater length makes it easier to focus the scanning electron beam near the corners of the image, and reduces the geometric distortion due to the large deflection angles of the electron beam in conventional tubes. The phosphor on the output face of the tube is especially selected to have brightness and spectral characteristics that facilitate the use of inexpensive motion picture film.

The kinescope electronics have two features not found in a normal TV monitor or receiver. These are two switches, one of which changes the direction of scanning of the electron beam from the normal left-to-right to right-to-left. The other switch changes the normal positive image to a negative image, in which dark and light areas are reversed. The significance of these changes will be explained in the next section. 


\section{FILM ORIENTATION PROBLEMS}

Commercial motion picture film is normally $35 \mathrm{~mm}$, and is produced by a negative-topositive method. The standard emulsion position in the projector is toward the lamp. On the other hand, $16 \mathrm{~mm}$ film was developed as an "amateur" film, and its standard emulsion position for projection is toward the lens. Amateur films are normally direct-positive reversal films. With both types of film it is not possible to reverse the film in a normal projector since the image is located off-center on the film because of the sound track on one side of the film.

Video programs are normally recorded photographically on $16 \mathrm{~mm}$ film, because the image quality of $16 \mathrm{~mm}$ film is entirely adequate to record all of the visual information in the video image, and the cost is less than for $35 \mathrm{~mm}$ film by at least a factor of 4 or 5 . If negative film is used to photograph a positive image on a kinescope, and a positive contact print is made from the negative for projection, the projected image is reversed left-to-right relative to the image on the kinescope. In order to correct for this reversal, the direction of scanning of the electron beam in the kinescope is reversed from left-to-right to right-to-left. When a positive print, made from a negative of such an image, is projected, the projected image is in the correct orientation. This is the process that is used to produce multiple prints of a video program.

If only a single print of the motion picture film is required, the simplest procedure is to photograph a negative image on the kinescope with negative film. When processed, this produces a positive image in the correct orientation for direct projection. This is probably the best way to prepare films of monochrome TV programs for archival storage.

A single print may also be made by photographing a positive image on the kinescope with direct-positive (reversal) film. This method is entirely satisfactory, but is more expensive, both for film and processing, than the use of negative film as described above.

\section{AUDIO RECORDING}

For archival storage the audio signal of the video program must be recorded optically. There are two basic forms of optical sound recording on motion picture film, variable density and variable area. Both methods are based on varying the light transmission of the sound track, so that light from a steady source is variably attenuated or modulated, and the transmitted light actuates a photocell to reproduce the sound signal. The fundamentals of optical sound reproduction are well covered in the literature and will not be repeated here.

There are two procedures used to produce the final sound track on motion pictures of video programs, usually referred to as the double system and single system. In the single system the sound track is recorded on the same film and at the same time the video image is photographed. The sound is recorded 26 frames behind the video. This is the process normally used when a single print is to be made, and is recommended for preparing films for archival storage. In the double system, the sound track is recorded at the time the video image is photographed to produce a negative image on film, but as a negative sound image on a separate roll of $16 \mathrm{~mm}$ film. The two films are contact printed on a single film to produce the final composite print. This procedure is usually followed if multiple prints of the film are to be made. It is considerably more expensive, but produces optimum quality of both picture and sound.

Because the kinescope screen is not extremely bright, relatively fast films normally produce the best picture and sound quality. Since the exposure time is fixed, the film exposure can only be varied by varying the brightness of the tube or the aperture of the lens. Fast films normally have larger grain size than slower films of the same type. Fine grain film is best for optical recording of audio signals, particularly at the higher frequencies. The film used for the single system recording is thus a compromise. However, it is recommended for the production of films for archival storage, in spite of the slight loss in audio quality. 


\section{PHOTOGRAPHIC EXPOSURE}

As mentioned above, the exposure time with a motion picture camera is fixed by the timing of the shutter, and the film exposure can only be varied by varying the illumination on the film during the exposure time. This illumination can only be varied in two ways, by varying the brightness of the image being photographed, or by varying the diaphragm setting of the camera lens.

Films used for kinescope recording of video programs are normally of the blue-sensitive type. The more expensive orthochromatic or panchromatic films are not required because the phosphor of the kinescope tube emits light that is predominantly in the blue-violet portion of the spectrum. Special films have been designed for this purpose.

The performance of photographic film is markedly affected by the process used in developing the film after exposure-the composition and temperature of each solution used, the time of immersion in each solution and the degree of agitation of the solution during immersion. Hence it is customary to talk about the characteristics of a film and a development process, rather than of either by itself. For simplicity in the following discussion only the film will be referred to, but the use of a standardized development process is implied.

The exposure characteristics of a film are described by its "characteristic curve," which is a plot of the optical density of the processed film as a function of the logarithm of the exposure producing the optical density. The characteristic curve is S-shaped. At exposures below the threshold level the optical density is that of the unexposed film. At exposures above the saturation level the density is that of the fully exposed film. At exposures between levels somewhat above threshold and somewhat below saturation, the curve is linear, and conforms to the equations

$$
\begin{gathered}
\mathrm{D}=\gamma \log \mathrm{H}+\mathrm{k} \text { and } \\
1 / \tau=\mathrm{KH}_{\gamma},
\end{gathered}
$$

where $\mathrm{D}$ is the optical density of the processed film, $\mathrm{H}$ is the exposure resulting in the density $\mathrm{D}$, $\tau$ is the transmittance of the processed film, and $\mathrm{k}$ and $\mathrm{K}$ are constants. The gamma of the film is evaluated as the slope of the linear portion of its characteristic curve. The length of the straightline portion of the curve is a measure of the exposure range or latitude of the film.

The film manufacturers recommend that film be calibrated for exposure to TV images as follows. First, expose the film to uniform raster patterns over a range of known brightness values. A uniform raster pattern is obtained by use of a video signal that consists of sync and blanking pulses only, with no picture signal. The brightness of the tube can be varied by means of the video-gain (brightness) control, or the grid-bias control on the kinescope. The tube brightness may be measured directly with a calibrated photometer with a response time long enough to give a steady reading, and a field of view large enough to give an average reading that does not change significantly with small shifts in position. As an alternative which may be more convenient, particularly when photographing actual programs, the beam current in the picture tube may, after calibration, be measured by means of a microammeter and taken as a measure of the tube brightness.

By changing the beam current, make a series of exposures at brightness levels differing by logarithmic steps. Control the development of the film to produce a gamma of about 0.6 to 0.7 for a negative, or 2.2 to 2.5 for a positive image. A high-gamma film produces the most pleasing projected images, but a low-gamma film negative produces the best prints. Measure with a densitometer the optical density of the processed film, and plot the density of the film as a function of the logarithm of the exposure (brightness), to obtain a characteristic curve for the film. For a negative film developed to a gamma of 0.65 , the range of densities in the negative of a video image will vary from about 0.2 to 1.5 . Select a brightness, or beam current, value near the center of this range, and use it as the preliminary exposure level for video images. With this exposure as a starting point, make a series of exposures of typical video images over a smaller range of brightness or beam current values, examine the processed film visually and select the exposure level that you prefer for each type of video picture. 
The procedure for evaluating exposure for positive images, either a negative photograph of a negative TV image or a direct positive image of a positive TV image, is similar, but the film is processed to produce a gamma of 2.2 to 2.5. The negative photographic image at a gamma of about 0.85 will have an exposure range of about 30 to 1 over the linear portion of the characteristic curve. A positive image at a gamma of about 2.5 will have an exposure range over the linear portion of the characteristic curve more on the order of 50 to 1 .

\section{BEAM RECORDING}

A recently developed alternative to kinescope recording for converting videotape recordings to motion picture film for archival storage deserves some mention. The kinescope and motion picture camera are both bypassed, and the scanning electron beam is incident directly on the film. By bypassing the phosphor screen and the camera optics, both of which introduce some image degradation, a better quality image is produced.

The film must be in a reasonably good vacuum, because a normal atmosphere would scatter the electron beam. If the entire roll of unexposed film were stored in the good vacuum, it would quickly be dried out, and the dry film would collect a charge from the scanning electron beam and repel or divert the beam on the second pass. What is done is to store the film in a moderate vacuum, of about 0.016 atmosphere, which is not low enough to dry the film excessively, but allows it to retain enough moisture to bleed off the charge developed by the electron beam. The film is fed through a vacuum seal to the film gate, where the atmospheric pressure is reduced to about $1 \times 10^{-6}$ atmosphere during exposure to the electron beam.

The midfield splice (fig. 1) is used to synchronize the video frame frequency with the motion picture frame frequency, with the added feature that the splice is made exact by counting the number of scanning lines in the two partial fields that are spliced, so that there is no gap and no overlap in the scanning.

In order to eliminate the raster lines in the film image, a $30 \mathrm{MHz}$ signal is used to wobble the beam vertically and thus to increase the width of the scanned lines until adjacent lines meet, and there is effectively no overlap and no space between scanning lines.

The electronics incorporates all of the features of the kinescope, such as reverse scanning of the electron beam and the production of either positive or negative images, and several other features that improve the quality of the recorded image, such as gamma correction, which will not be discussed in detail.

The audio signal is recorded optically, as in kinescope recording.

In brief, the electron beam recording system, when operating properly, produces an image on the film that is better in several respects than that produced by kinescope recording. The initial cost of the equipment is higher, but the operating cost should not be appreciably higher if existing maintenance problems can be solved. With presently available equipment, maintenance has been reported to be a continuing problem, and the use of electron beam recording is not recommended until the maintenance problems have been solved.

\section{LASER BEAM RECORDING}

Equipment in which a laser beam replaces the scanning electron beam in electron beam recording is in an advanced stage of development. The laser beam is modulated with the video signal, and is scanned over the film by means of nutating mirrors rotating about axes that are horizontal and vertical to the image, respectively. This equipment is not yet available commercially, but when perfected, it should be free from the maintenance problems of the electron beam method because no vacuum is required. This method has the potential of producing films that are equal in quality to those produced by electron beam recording when such equipment is operating properly. 


\section{COSTS}

The cost for equipment to convert videotape information to motion picture film for archival storage is so high that its purchase can be justified only if the equipment has a fairly high use factor. If the amount of tape to be converted is small, only a few hours of videotape a day, it may be more satisfactory from both a cost and quality standpoint to have the tape converted by a commercial laboratory.

A monochrome kinescope and rapid-pulldown camera, sold as a unit, costs on the order of $\$ 85,000$. Because the videotape must be converted in real time the maximum capacity of such a unit is about 6 hours of videotape per 8-hour day, or perhaps 18 to 19 hours of tape if operated 24 hours a day. Average production will probably be somewhat less. An automatic processing unit for motion picture film to handle the output of one kinescope camera will cost a minimum of about $\$ 20,000$. A larger unit, costing about $\$ 30,000$ to $\$ 35,000$, can handle the output of several kinescope cameras without trouble.

Operating costs of a large laboratory, operating near capacity, will be in the range of $\$ 60$ to $\$ 150$ per hour of tape converted, including supplies (principally film and processing chemicals) and direct labor, but not overhead. This is based on preparing a direct positive film (photographing a negative image on negative film) with integral (single system) sound, which should be entirely adequate for archival storage. There is likely to be some slight degradation of sound quality, particularly at the higher audio frequencies, in such film, but the image quality should be as good as the video image. The degradation in sound quality should not affect the intelligibility of speech. If double system sound is used, in which the picture and sound are recorded on separate negative films, which are processed and printed on a single film to produce the final positive print, the cost will be increased by a factor of 3 to 4 , and additional equipment will be required for recording the separate sound track and printing the film. This latter procedure produces a motion picture film of highest quality, suitable for theater presentation.

There are numerous processing laboratories, several each in the Los Angeles and New York areas and one or more in most of the other large cities, that convert videotape infornation to motion picture film. There is a wide range in the price for this service, depending to some extent on the quantity of tape to be converted, and the time permitted for the conversion. In general the rates will vary from about $\$ 2.50$ to $\$ 10$ per minute of tape on a time available basis (where the turnaround time may be as much as a month) to $\$ 8$ to $\$ 15$ per minute of tape for 24-hour service, all based on a single positive print (no negative) with single system sound. There is usually a flat rate charge of $\$ 50$ to $\$ 100$ for each tape, in addition to the time charge.

\section{SUMMARY}

Magnetic video tape is not an archival material. It deteriorates with time, even under ideal storage conditions, to the extent that there is some detectable degradation of video and audio quality in times of 5 years or less, and noticeable degradation in periods of 20 years or more. Motion picture film, on the other hand, is an archival material, when properly processed, handled and stored.

The technology and equipment for converting audio and video signals recorded on videotape to pictures and an optical sound track on motion picture film are commercially available. Of the several systems now available, the kinescope system with a rapid-pulldown camera appears to be the most suitable. The laser scanner system now under development has the potential of reducing cost of equipment and improving quality when fully developed. The conversion of videotape to motion picture film is also offered as a service by numerous commercial laboratories.

The decision between using a commercial laboratory service, or setting up an in-house facility for making the conversion must be made on the basis of cost and convenience. 


\section{BIBLIOGRAPHY}

1. Federal Property Management Regulation, Amendment B-33. Subpart 101-11.5, Microfilming, March 1976.

2. Federal Specification, Film, Photographic and Film, Photographic, Processed, Fed. Std. No. 125C, March 26, 1976. General Services Administration, Specification Sales, Building 197 (Washington Navy Yard), Washington, DC 20407.

3. Practice for Storage of Processed Safety Photographic Film. ANSI PH1.43-1975, American National Standards Institute, 1430 Broadway, New York, NY 10018.

4. Specifications for Photographic Film for Archival Records, Silver-Gelatin Type, on Cellulose Ester Base. ANSI PH1.28-1976, American National Standards Institute, 1430 Broadway, New York, NY 10018.

5. Specifications for Safety Photographic Film. ANSI PH1.25-1976, American National Standards Institute, 1430 Broadway, New York, NY 10018. 



\section{ANNOUNCEMENT OF NEW PUBLICATIONS ON NATIONAL CRIME AND RELATED SUBJECTS}

Superintendent of Documents, Government Printing Office,

Washington, D.C. 20402

Dear Sir:

Please add my name to the announcement list of new publications to be issued on the above subjects (including this NBS series):

Name

Company

Address

City State Zip Code

(Notification Key N-538) 




\section{U.S. DEPARTMENT OF COMMERCE}

National Bureau of Standards

Washington, D.C. 20234

POSTAGE ANO FEES PAIO U.S. OEPARTMENT OF COMMERCE COM-295

SPECIAL FOURTH-CLASS RATE

BOOK

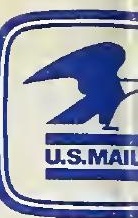

Penalty for Private Use, $\mathbf{\$ 3 0 0}$ 